\title{
Produção de biomassa e óleo essencial em mil folhas cultivada sob telas coloridas
}

\section{José EBP Pinto*; Elza O Ferraz; Suzan KV Bertolucci; Helbert RO Silveira; Aurislaine R Santos; Giselly M Silva}

${ }^{1}$ UFLA-DAG, Lab. Cultura de Tecidos Vegetais e Plantas Medicinais, C. Postal 3037, 37200-000 Lavras-MG; jeduardo@dag.ufla.br (autor para correspondência); elza.o.ferraz@hotmail.com; suzan@dag.ufla.br; helbert_rezende@yahoo.com.br; auris_laine@hotmail.com; gisellymota@yahoo.com.br

\section{RESUMO}

Objetivou-se avaliar a produção de biomassa, óleo essencial, pigmentos e carboidratos em plantas de mil-folhas sob malhas coloridas. As plantas foram cultivadas em cinco ambientes: pleno sol, sob Aluminet ${ }^{\mathbb{R}}$ e malhas preta, azul e vermelha (50\% de irradiância). $\mathrm{O}$ experimento foi realizado em delineamento inteiramente casualizado, com quatro repetições e quatro plantas por parcela, sendo uma planta por vaso. As avaliações foram realizadas em duas épocas de colheita, a primeira aos 120 dias e a segunda aos 180 dias após o plantio (rebrota). O acúmulo máximo de biomassa seca da parte aérea $\left(36,8\right.$ g planta $\left.^{-1}\right)$ e rendimento de óleo $\left(4,45\right.$ g planta $\left.^{-1}\right)$ ocorreram sob pleno sol, na segunda colheita. O principal constituinte do óleo foi o camazuleno, o qual apresentou faixa de variação entre 19,9 e 46,9\%. O cultivo ao pleno sol proporcionou maior acúmulo de biomassa e rendimento de óleo essencial. Houve diferenças qualitativas e quantitativas dos constituintes do óleo essencial dentre os tratamentos.

Palavras-chave: Achillea millefolium, malhas fotoconversoras, compostos voláteis, planta medicinal.

\section{ABSTRACT}

Biomass production and essential oil in yarrow cultivated under colored screen types

We evaluated the production of biomass, essential oil, pigments and carbohydrates in plants of yarrow grown under colored screen types. Plants were grown in five environments: full sunlight and under Aluminet ${ }^{\mathbb{R}}$ and black, blue and red screens (50\% irradiance). The experiment was carried out in a completely randomized design with four replications and four plants per plot, one plant per pot. Evaluations were done in two moments, the first one at 120 days and the second one at 180 days after planting (regrowth). The highest dry biomass of shoots $\left(36.8 \mathrm{~g} \mathrm{plant}^{-1}\right)$ and oil yield $\left(4.45 \mathrm{~g} \mathrm{plant}^{-1}\right)$ were obtained under full sunlight in the second crop. The major oil constituent was chamazulene, which ranged between 19.9 to $46.9 \%$. Growing in full sunlight provides greater accumulation of biomass and essential oil yield. Qualitative and quantitative chemical difference were found in the essential oil compounds among the treatments.

Keywords: Achillea millefolium, chromatinet, volatile composition, medicinal plant.

(Recebido para publicação em 5 de abril de 2013; aceito em 6 de junho de 2014) (Received on April 5, 2013; accepted on June 6, 2014)

\begin{abstract}
luz é o principal fator que controla o crescimento, o desenvolvimento e o metabolismo das plantas. No entanto, a intensidade luminosa e a qualidade espectral podem causar alterações morfofisiológicas no vegetal (Meira et al., 2012). Uma das ferramentas utilizadas para manipular o espectro de luz transmitida às plantas é o uso de malhas. As malhas coloridas representam uma tecnologia agrícola, que reúne a proteção física do ambiente de cultivo com a filtragem diferencial da radiação solar, para promover respostas fisiológicas desejáveis, reguladas pela luz (Henrique et al., 2011).
\end{abstract}

A malha preta (sombrite) é considerada neutra e auxilia apenas na redução da incidência de radiação sobre as plantas, sem influência na qualidade espectral da luz. A malha vermelha reduz as ondas azuis, verdes e amarelas e acrescenta ondas na faixa espectral do vermelho e do vermelho distante, com transmitância para comprimentos de ondas superiores a $590 \mathrm{~nm}$. A malha azul filtra as ondas na faixa do vermelho e do vermelho distante, o que permite a passagem de ondas com transmitância na região do azul-verde (400-540 nm) (Nomura et al., 2009; Costa et al., 2012). A malha Aluminet ${ }^{\circledR}$ altera as propriedades da radiação, aumentando sua reflexão, além de permitir controle de temperatura (Polysack, 2011).

Estudos com plantas medicinais têm demonstrado a influência do uso de malhas fotoconversoras no acúmulo de biomassa e produção de óleos essenciais, como foi constatato em Baccharis trimera (Silva et al., 2006), Melissa officinalis (Brant et al., 2009), Ocimum selloi (Costa et al., 2010) e Mentha piperita (Costa et al., 2012). Porém, as respostas quanto à intensidade e qualidade da luz são particulares para cada espécie. 
A Achillea millefolium (Asteraceae), conhecida popularmente por mil folhas, é uma das espécies que constam da Relação Nacional de Plantas Medicinais de Interesse ao SUS (RENISUS), que trata de uma lista de espécies vegetais com potencial de avançar nas etapas da cadeia produtiva e de gerar produtos de interesse ao SUS (Brasil, 2009). A mil folhas é especialmente utilizada pela sua ação analgésica, anti-inflamatória e antiespasmódica (Brasil, 2010). Entretanto, até o momento, os conhecimentos acerca de suas práticas agronômicas são incipientes. Lima et al. (2011), em estudo com a espécie em ambiente sombreado e não sombreado, inferiram relação positiva no acúmulo de biomassa seca e pigmentos fotossintetizantes nas plantas cultivadas a pleno sol. Contudo, referências acerca do desempenho da espécie a diferentes faixas de radiação solar são relevantes, a fim de adequar melhores condições de cultivo associadas à alta produção de biomassa e síntese de compostos bioativos. Objetivou-se, com este trabalho, avaliar a influência de malhas coloridas na produção de biomassa, óleo essencial, pigmentos fotossintetizantes e carboidratos em plantas de mil folhas.

\section{MATERIAL E MÉTODOS}

O ensaio foi realizado em vasos, sob telados, na Fazenda Gota da Esperança ( $21^{\circ} 14^{\prime} 07^{\prime \prime} \mathrm{S}, 44^{\circ} 58^{\prime} 22^{\prime \prime} \mathrm{O}, 879 \mathrm{~m}$ de altitude), na Universidade Federal de Lavras (UFLA) entre abril e outubro de 2010.

Mudas de mil folhas obtidas por propagação de rizomas foram transplantadas para vasos plásticos com capacidade de $10 \mathrm{~L}$, contendo terra (Latossolo Vermelho escuro) misturada com $6 \mathrm{~kg} \mathrm{~m}^{-3}$ de esterco bovino. A terra e o esterco bovino foram analisados pelo Laboratório de Análise de Solos da UFLA. As características químicas do solo foram: $\mathrm{pH}$ em água $=5,6$; $\mathrm{P}$ e K $\left(\mathrm{mg} \mathrm{dm}{ }^{-3}\right)=0,6$ e 14; $\mathrm{Ca}^{2+}, \mathrm{Mg}^{2+}, \mathrm{Al}^{3+}$, $\mathrm{H}+\mathrm{Al}\left(\mathrm{cmolc} \mathrm{dm}^{-3}\right)=0,5 ; 0,1 ; 0,0 ; 2,1$; saturação de bases $\mathrm{V}(\%)=23,4$; matéria orgânica $\left(\operatorname{dag~kg}{ }^{-1}\right)=1,4$. Do esterco bovino, foram: $\mathrm{N}, \mathrm{P}, \mathrm{K}, \mathrm{Na}, \mathrm{Ca}, \mathrm{Mg}, \mathrm{S}$ (g $\left.\mathrm{kg}^{-1}\right)=18,0 ; 5,1 ; 13,0 ; 1,5 ; 4,1 ; 3,2 ; 2,6$;
$\mathrm{B}, \mathrm{Cu}, \mathrm{Fe}, \mathrm{Mn}, \mathrm{Zn}\left(\mathrm{mg} \mathrm{g}^{-1}\right)=5,6 ; 39,0$; $12.848,0 ; 461,0 ; 150,0$.

$\mathrm{O}$ experimento foi conduzido em delineamento inteiramente casualizado com cinco tratamentos e quatro repetições constituídas por quatro plantas. Os tratamentos foram as malhas fotoconversoras preta (sombrite), aluminizada (Aluminet $\left.^{\circledR}\right)$, azul $\left(\right.$ ChromatiNet $\left.^{\circledR}\right)$, vermelha $\left(\right.$ ChromatiNet $\left.^{\mathbb{R}}\right)$ e pleno sol. As malhas avaliadas compunham de telados que interceptaram a radiação solar em $50 \%$ e foram construídos com 2,10 x 7,85 x 7,35 m (altura, comprimento e largura, respectivamente). Foram realizadas duas colheitas das plantas, sendo a primeira aos 120 dias após o plantio, quando colheram-se as folhas, e a segunda aos 180 dias após o plantio, quando colheram-se as plantas inteiras (folhas, raízes e rizomas). Tanto na primeira quanto na segunda colheitas, as partes das plantas foram acondicionadas em sacos de papel kraft e secas em estufa com circulação forçada de ar a $38 \pm 2^{\circ} \mathrm{C}$, até massa constante. Na primeira colheita determinou-se o acúmulo de biomassa seca das folhas e, na rebrota, acúmulo de biomassa seca da parte aérea (folhas) e da parte subterrânea (raízes + rizomas), além da relação parte subterrânea:parte aérea.

A quantificação dos pigmentos e carboidratos foi realizada apenas nas amostras de folhas da segunda colheita. Para as análises bioquímicas foram retiradas ao acaso duas folhas completamente expandidas de plantas de cada tratamento. As análises das clorofilas $a$, $b$, total e carotenóides foram realizadas conforme metodologia de Lichtenthaler \& Buschmann (2001). A quantificação de açúcares solúveis totais e de amido foi realizada conforme Yemm \& Willis (1954) e Allen et al. (1974), a partir de folhas e da parte subterrânea.

O óleo essencial foi extraído das folhas secas das duas colheitas, a partir de uma amostra composta constituída das quatro plantas de cada repetição. De cada amostra composta tomou-se uma alíquota de cerca de $40 \mathrm{~g}$ de biomassa seca, as quais foram hidrodestiladas em aparelho de Clevenger modificado por $90 \mathrm{~min}$. O óleo essencial foi purificado por partição líquido-líquido com diclorometano e tratado com sulfato de magnésio anidro. Após esse período, a solução foi filtrada e o solvente evaporado sob capela de exaustão de gases. Foram determinados o teor e o rendimento do óleo essencial na base seca da parte aérea.

A composição química do óleo foi determinada por uma amostra composta obtida pelo agrupamento de massas equivalentes do óleo essencial das repetições de cada tratamento. A análise química quantitativa foi realizada em um sistema de cromatografia gasosa acoplado a um detector de ionização em chama de hidrogênio Agilent ${ }^{\mathbb{B}}$ 7890A equipado com coluna capilar HP-5MS $(30 \mathrm{~m} \times 0,25 \mathrm{~mm} \times 0,25 \mu \mathrm{m})($ Califórnia, EUA). Utilizou-se hélio como gás de arraste com fluxo de $1,0 \mathrm{~mL} \mathrm{~min}^{-1}$; as temperaturas do injetor e do detector foram mantidas em $220^{\circ} \mathrm{C}$ e $240^{\circ} \mathrm{C}$, respectivamente. A temperatura inicial do forno foi de $60^{\circ} \mathrm{C}$ com uma rampa de temperatura de $3^{\circ} \mathrm{C} \mathrm{min}^{-1}$ até $150^{\circ} \mathrm{C}$, seguido por uma isoterma de $10 \mathrm{~min}$ e, posteriormente, de uma rampa de $10^{\circ} \mathrm{C}$ $\mathrm{min}^{-1}$ até $270^{\circ} \mathrm{C}$. O óleo foi diluído em acetato de etila $(1 \%, \mathrm{v} / \mathrm{v})$ e $1,0 \mu \mathrm{L}$ foi injetado automaticamente no modo split a uma razão de 1:50. As análises qualitativas do óleo foram realizadas por cromatografia gasosa acoplada à espectrometria de massas (CG-EM), utilizando-se um equipamento Agilent ${ }^{\mathbb{B}}$ 5975C, operado por ionização de impacto eletrônico a $70 \mathrm{eV}$, em modo varredura, a uma velocidade de 1,0 scan s$^{-1}$, com intervalo de aquisição de massas de $40-400 \mathrm{~m} / \mathrm{z}$. As condições cromatográficas foram as mesmas empregadas nas análises quantitativas. Os componentes foram identificados por comparação de seus índices de retenção com dados de espectros de massas e índices de retenção de literaturas (Adams, 2007; Kotan et al., 2010) e por comparação dos espectros de massas com os da biblioteca NIST (2008).

Os dados foram submetidas à análise de variância, pelo teste de $\mathrm{F}$ e aplicado o teste de Scott \& Knott $(p<0,05)$, empregando-se programa estatístico Sisvar ${ }^{\circledR}$, versão 5.0 (Ferreira, 2011).

\section{RESULTADOS E DISCUSSÃO}

As intensidades luminosas sob as 
Tabela 1. Produção de biomassa seca da parte aérea, teor de óleo essencial, rendimento de óleo essencial, biomassa seca da parte subterrânea, relação parte subterrânea/parte aérea, pigmentos fotossintetizantes e carboidratos na primeira e segunda colheitas de Achillea millefolium cultivadas sob várias malhas (biomass dry weight of shoots, content of essential oil, essential oil yield, root dry mass, root/shoot ratio, carbohydrates and photosynthetic pigments production in first and second harvest of Achillea millefolium grown under diferente screen types). Lavras, UFLA, 2010.

\begin{tabular}{|c|c|c|c|c|c|}
\hline \multirow{2}{*}{ Características avaliadas } & Preta & Vermelha & Azul & Aluminet & Pleno sol \\
\hline & \multicolumn{5}{|c|}{$1^{\text {a }}$ colheita } \\
\hline \multirow{3}{*}{$\begin{array}{l}\text { Biomassa parte aérea (g/planta) } \\
\text { Teor de óleo essencial (mg/100 g biomassa seca das } \\
\text { folhas) } \\
\text { Rendimento de óleo essencial ( } \mathrm{g} / \text { planta) }\end{array}$} & $9,80 \mathrm{c}$ & $13,70 \mathrm{~b}$ & $12,00 \mathrm{~b}$ & $22,60 \mathrm{a}$ & - \\
\hline & $40,00 \mathrm{a}$ & $37,00 \mathrm{a}$ & $36,00 \mathrm{a}$ & $26,00 \mathrm{a}$ & - \\
\hline & $0,40 \mathrm{~b}$ & $0,51 \mathrm{a}$ & $0,44 \mathrm{~b}$ & $0,59 \mathrm{a}$ & - \\
\hline & \multicolumn{5}{|c|}{$2^{\mathrm{a}}$ colheita } \\
\hline Biomassa parte aérea (g/planta) & $25,70 \mathrm{c}$ & $29,70 \mathrm{~b}$ & $25,80 \mathrm{c}$ & $35,50 \mathrm{a}$ & $36,80 \mathrm{a}$ \\
\hline Biomassa seca parte subterrânea (g/planta) & $26,00 \mathrm{~b}$ & $42,50 \mathrm{a}$ & $22,50 \mathrm{~b}$ & $17,70 \mathrm{~b}$ & $49,10 \mathrm{a}$ \\
\hline Parte subterrânea/parte aérea & $1,00 \mathrm{~b}$ & $1,40 \mathrm{a}$ & $0,90 \mathrm{~b}$ & $0,50 \mathrm{c}$ & $1,30 \mathrm{a}$ \\
\hline $\begin{array}{l}\text { Teor de óleo essencial } \\
\text { (mg } 100 \mathrm{~g}^{-1} \text { biomassa seca das folhas) }\end{array}$ & $87,00 \mathrm{~b}$ & $94,00 \mathrm{~b}$ & $59,00 \mathrm{c}$ & $53,00 \mathrm{c}$ & $121,00 \mathrm{a}$ \\
\hline \multirow[t]{2}{*}{ Rendimento de óleo essencial (g planta $\left.{ }^{-1}\right)$} & $2,23 \mathrm{c}$ & $2,79 \mathrm{~b}$ & $1,52 \mathrm{~d}$ & $1,88 \mathrm{~d}$ & $4,45 \mathrm{a}$ \\
\hline & \multicolumn{5}{|c|}{ Pigmentos fotossintetizantes (mg/g biomassa da parte aérea fresca) } \\
\hline Clorofila $a$ & $1,00 \mathrm{a}$ & $1,10 \mathrm{a}$ & $1,20 \mathrm{a}$ & $1,10 \mathrm{a}$ & $0,90 \mathrm{a}$ \\
\hline Clorofila $b$ & $1,20 \mathrm{a}$ & $0,70 \mathrm{~b}$ & $0,40 \mathrm{~b}$ & $1,30 \mathrm{a}$ & $0,70 \mathrm{~b}$ \\
\hline Clorofila $a / b$ & $0,90 \mathrm{c}$ & $1,60 \mathrm{~b}$ & $2,90 \mathrm{a}$ & $0,90 \mathrm{c}$ & $1,30 \mathrm{~b}$ \\
\hline Clorofila total & $2,30 \mathrm{a}$ & $1,80 \mathrm{~b}$ & $1,60 \mathrm{~b}$ & $2,40 \mathrm{a}$ & $1,60 \mathrm{~b}$ \\
\hline \multirow[t]{2}{*}{ Carotenóides } & $0,12 b$ & $0,14 \mathrm{~b}$ & $0,24 \mathrm{a}$ & $0,05 \mathrm{c}$ & $0,16 b$ \\
\hline & \multicolumn{5}{|c|}{ Carboidratos (mg/g biomassa seca) } \\
\hline Açúcar solúvel total na folha & $4,0 \mathrm{a}$ & $2,6 b$ & $2,4 \mathrm{~b}$ & $2,3 b$ & $4,0 \mathrm{a}$ \\
\hline Açúcar solúvel total na parte subterrânea & $28,1 \mathrm{a}$ & $24,1 \mathrm{~b}$ & $22,7 b$ & $23,2 b$ & $28,9 \mathrm{a}$ \\
\hline Amido folha & $0,5 b$ & $0,5 b$ & $0,3 \mathrm{c}$ & $0,3 \mathrm{c}$ & $0,7 \mathrm{a}$ \\
\hline Amido raiz & $4,1 \mathrm{a}$ & $2,9 \mathrm{~b}$ & $2,3 b$ & $4,0 \mathrm{a}$ & $3,3 \mathrm{a}$ \\
\hline
\end{tabular}

Médias seguidas pelas mesmas letras nas linhas não diferem entre si pelo teste de Scott \& Knott $(p<0,05)$ [means followed by the same letter in line do not differ by Scott \& Knott test $(\mathrm{p}<0.05)]$.

malhas foram mensuradas com um medidor digital portátil Spectrum ${ }^{\circledR}$ (Spectrum Technologies, Plainfield-IL). As leituras indicaram intensidades de 920, 850, 850, 950 e $1970 \mu \mathrm{mol} \mathrm{m}^{-2} \mathrm{~s}^{-1}$, respectivamente, para as malhas preta, azul, vermelha, Aluminet ${ }^{\mathbb{B}}$ e pleno sol.

As plantas da área experimental em condições de luz solar plena foram perdidas. Por isso, para esse ambiente foi avaliada apenas a rebrota. Houve interferência da qualidade espectral na produção de biomassa, pigmentos, carboidratos e óleo essencial (Tabelas 1 e 2).

Na primeira colheita, observou-se que as plantas cultivadas sob aluminet apresentaram maior acúmulo de biomassa seca da parte aérea, diferindo estatisticamente das demais (Tabela 1). $\mathrm{O}$ menor acúmulo foi observado sob a malha preta. Na segunda colheita, a maior produção de biomassa seca da parte aérea ocorreu nas plantas cultivadas ao pleno sol e aluminet, sendo estas estatisticamente iguais entre si. Entretanto, no cultivo sob pleno sol o acúmulo de biomassa seca da parte subterrânea foi estatisticamente superior em relação ao aluminet.

Para a biomassa seca da parte subterrânea não houve diferenças entre as malhas preta, azul e aluminet, as quais apresentaram os menores índices de crescimento. Nos cultivos a pleno sol e malha vermelha ocorreu maior acúmulo de biomassa seca da parte subterrânea, bem como, maior relação parte subterrânea/parte aérea. Segundo Chagas et al. (2010), o aumento da intensidade luminosa pode provocar maior drenagem de fotoassimilados para as raízes, aumentando a proporção de biomassa entre parte subterrânea e parte aérea.
A qualidade espectral da malha pode ter sido responsável pelo maior direcionamento da biomassa seca para a parte subterrânea. As telas vermelhas transferem mais a luz do espectro nas ondas do vermelho e vermelho distante e difundem a luz que passa através da malha, sendo eficiente no desenvolvimento da planta (Li, 2006). No entanto, esse acúmulo de biomassa seca da parte subterrânea não foi resultado do armazenamento de amido, pois assim como sob malha azul, sob a vermelha, as plantas apresentaram o menor teor desse carboidrato de reserva na raiz (Tabela 1).

Pouco ainda se sabe sobre os mecanismos fisiológicos relacionados às respostas das plantas cultivadas em condições de radiação seletiva. Porém, o que se pode afirmar é que a mil folhas não respondeu positivamente ao cultivo protegido, já que a radiação solar plena 
Tabela 2. Composição química do óleo essencial de folhas de plantas de mil folhas cultivadas sob malhas coloridas, em duas colheitas (chemical composition of the essential oil in the first and second harvests of Achillea millefolium cultivated under colored screen types). Lavras, UFLA, 2010.

\begin{tabular}{|c|c|c|c|c|c|c|c|c|c|c|}
\hline \multirow{3}{*}{ Constituinte } & \multirow{3}{*}{$\mathrm{IR}^{*}$} & \multirow{2}{*}{\multicolumn{2}{|c|}{ Preta }} & \multirow{2}{*}{\multicolumn{2}{|c|}{ Vermelha }} & \multicolumn{2}{|c|}{ Azul } & \multicolumn{2}{|c|}{ Aluminet } & \multirow[t]{2}{*}{ Pleno sol } \\
\hline & & & & & & \multicolumn{4}{|c|}{ Colheitas } & \\
\hline & & $\mathbf{1}^{\mathrm{a}}$ & $2^{a}$ & $1^{\mathrm{a}}$ & $2^{a}$ & $\mathbf{1}^{\mathrm{a}}$ & $2^{a}$ & $\mathbf{1}^{\mathrm{a}}$ & $2^{a}$ & $2^{a}$ \\
\hline$\gamma$-terpineno & 1059 & nd & 0,3 & nd & 0,2 & nd & nd & nd & nd & 0,3 \\
\hline borneol & 1152 & 1,4 & 4,0 & 1,1 & 3,4 & 2,4 & 1,6 & 6,4 & 2,7 & 5,7 \\
\hline$\alpha$-terpineol & 1163 & nd & 0,8 & nd & 0,6 & nd & 0,2 & nd & 0,2 & 1,2 \\
\hline terpinen-4-ol & 1178 & 0,5 & 1,2 & 0,4 & 1,0 & nd & 0,5 & 1,2 & 0,8 & 1,3 \\
\hline$Z$-cariofileno & 1409 & 0,8 & 2,7 & 0,9 & 2,8 & 1,4 & 1,9 & 1,4 & 1,8 & 3,2 \\
\hline aromadendreno & 1442 & nd & 0,5 & nd & 0,6 & nd & 0,4 & nd & 0,4 & 0,6 \\
\hline$\beta$-cubebeno & 1470 & 8,5 & 12,8 & 7,9 & 18,2 & 7,7 & 7,6 & 3,8 & 5,0 & 12,5 \\
\hline$\beta$-ionona & 1476 & 0,3 & 0,2 & 0,2 & 0,2 & nd & 0,2 & nd & 0,3 & 0,2 \\
\hline germacreno D & 1485 & 0,8 & 1,1 & 0,8 & 1,5 & nd & 0,7 & nd & 0,5 & 0,9 \\
\hline$\alpha$-farneseno & 1498 & 3,0 & 3,7 & 3,1 & 5,6 & 3,0 & 2,3 & 1,8 & 1,6 & 2,7 \\
\hline cubebol & 1511 & nd & 0,3 & nd & 0,4 & nd & 0,3 & nd & nd & 0,3 \\
\hline$\delta$-cadineno & 1513 & 0,3 & 0,2 & 0,2 & 0,2 & nd & 0,2 & nd & nd & 0,2 \\
\hline$\delta$-cadineno & 1524 & 0,3 & 0,6 & 0,3 & 0,5 & nd & 0,6 & nd & 0,5 & 0,3 \\
\hline cis-nerolidol & 1540 & 0,7 & 0,7 & 0,6 & 0,5 & 1,4 & 0,8 & 1,0 & 0,8 & 0,5 \\
\hline$\alpha$-calacoreno & 1543 & nd & 0,5 & nd & 0,4 & nd & 0,4 & nd & 0,5 & 0,2 \\
\hline óxido de aromadendreno & 1550 & 2,2 & 3,1 & 2,4 & 2,7 & 0,4 & 3,6 & 1,3 & 2,5 & 2,7 \\
\hline cis-muurol-5-en-4- $\beta$-ol & 1551 & nd & nd & nd & nd & nd & nd & 1,1 & nd & $\mathrm{Nd}$ \\
\hline espatulenol & 1561 & 5,2 & 4,1 & 4,8 & 3,7 & 7,7 & 4,6 & 6,2 & 4,4 & 3,2 \\
\hline$E$-nerolidol & 1566 & 2,1 & 2,6 & 2,0 & 2,4 & 3,5 & 2,9 & 2,9 & 3,7 & 3,8 \\
\hline álcool de cariofilenila & 1571 & 0,3 & 0,3 & 0,4 & 0,3 & nd & 0,4 & nd & 0,3 & 0,4 \\
\hline hidrato de sesquisabineno & 1574 & 0,3 & 0,1 & 0,3 & 0,2 & nd & 0,2 & nd & nd & 0,3 \\
\hline óxido de cariofileno & 1576 & 0,8 & 1,1 & 0,9 & 0,8 & 1,6 & 1,2 & 1,5 & 1,6 & 1,0 \\
\hline globulol & 1588 & 0,4 & 0,2 & 0,4 & 0,2 & nd & 0,2 & nd & nd & 0,2 \\
\hline$\beta$-copaen-4-ol & 1590 & 0,8 & 0,6 & 0,8 & 0,4 & nd & 0,7 & 1,2 & 1,1 & 0,6 \\
\hline viridiflorol & 1594 & 1,4 & 0,6 & 1,6 & 0,7 & 2,0 & 0,7 & 1,7 & 0,7 & 0,6 \\
\hline ledol & 1604 & 0,6 & 0,4 & 0,5 & 0,3 & nd & 0,4 & nd & 0,4 & 0,3 \\
\hline epoxido de humuleno & 1606 & 1,4 & nd & 0,9 & 0,2 & nd & nd & nd & nd & $\mathrm{Nd}$ \\
\hline oxido de $\beta$-himachaleno & 1618 & 0,9 & nd & 0,7 & nd & nd & nd & nd & nd & 0,1 \\
\hline cubenol & 1621 & nd & 0,4 & nd & nd & nd & 0,4 & 1,1 & 0,2 & 0,3 \\
\hline 10-epi- $\gamma$-eudesmol & 1625 & 1,6 & 1,0 & 1,4 & 1,4 & 2,2 & 1,1 & 1,6 & 0,8 & 0,8 \\
\hline 1-epi-cubenol & 1630 & 1,6 & 0,8 & 1,4 & 0,8 & 2,5 & 0,8 & 1,8 & 0,7 & 0,6 \\
\hline$\gamma$-eudesmol & 1633 & nd & 0,3 & 0,7 & 0,3 & nd & 0,4 & 1,0 & 0,4 & 0,3 \\
\hline $\begin{array}{l}\alpha / \beta \text {-cariofila-4(14),8(15)- } \\
\text { dien-5-ol }\end{array}$ & 1637 & 2,3 & 2,1 & 2,0 & 1,1 & 6,1 & 2,3 & 4,1 & 2,2 & 1,0 \\
\hline t-muurolol & 1639 & 1,7 & 0,2 & 1,8 & 1,0 & nd & nd & nd & 0,5 & 0,7 \\
\hline óxido de $\alpha$-bisabolol B & 1648 & 1,5 & 0,3 & 0,9 & 0,3 & nd & 0,4 & 1,0 & 0,4 & 0,3 \\
\hline$\beta$-eudesmol & 1652 & 0,8 & 0,3 & 0,6 & 0,2 & nd & 0,3 & nd & 0,4 & 0,2 \\
\hline selin-11-en-4- $\alpha$-ol & 1657 & 0,7 & 0,2 & nd & 0,3 & nd & nd & nd & nd & 0,2 \\
\hline 14-hidroxi-9-epi- $\beta$-cariofileno & 1668 & 1,8 & 0,5 & 1,2 & 0,8 & 2,4 & 1,0 & 1,1 & 1,5 & 0,4 \\
\hline$\alpha$-cadinol & 1676 & 5,0 & 1,6 & 3,2 & 2,1 & 4,7 & 1,6 & 3,1 & 1,7 & 2,0 \\
\hline$\alpha$-bisabolol & 1683 & 0,7 & 0,6 & nd & nd & nd & 0,7 & nd & 0,8 & $\mathrm{Nd}$ \\
\hline 2Z,6Z-farnesol & 1701 & 1,3 & 0,7 & 1,0 & 0,6 & 1,8 & 0,9 & 2,3 & 1,0 & 0,6 \\
\hline camazuleno & 1734 & 28,7 & 36,8 & 35,2 & 33,9 & 26,0 & 46,1 & 19,9 & 46,9 & 41,0 \\
\hline 14-hidroxi- $\alpha$-muuroleno & 1779 & 2,1 & 1,6 & 1,4 & 1,2 & 4,0 & 1,7 & 4,2 & 1,6 & 1,1 \\
\hline acetato de $\beta$-eudesmol & 1791 & 1,5 & 1,6 & 1,1 & 1,1 & 2,9 & 2,4 & 3,8 & 2,0 & 1,2 \\
\hline acetato de $\alpha$-bisabolol & 1800 & 7,2 & 1,5 & 9,0 & 1,1 & 9,3 & nd & 10,2 & 2,0 & 1,3 \\
\hline oxido de isolongifolol & 1816 & 0,7 & 0,5 & 0,5 & 0,4 & nd & 0,6 & 1,6 & 0,5 & 0,3 \\
\hline 2E,6E-acetato de farnesila & 1849 & 0,7 & 0,4 & 0,4 & 0,3 & nd & 0,4 & 1,4 & 0,5 & 0,2 \\
\hline Z,Z-farnesil acetona & 1857 & 1,8 & 0,9 & 0,9 & 0,8 & 1,8 & 0,8 & 1,7 & 0,8 & 0,7 \\
\hline hexahidro-farnesilacetona & 1905 & 1,1 & 0,3 & 0,7 & 0,2 & 2,6 & 0,4 & 2,8 & 0,6 & 0,2 \\
\hline Monoterpenos totais & & 1,9 & 6,3 & 1,5 & 5,2 & 2,4 & 2,3 & 7,6 & 3,7 & 8,5 \\
\hline Sesquiterpenos totais & & 93,9 & 89,0 & 93,1 & 90,7 & 92,0 & 92,6 & 86,6 & 91,6 & 88,2 \\
\hline Total & & 95,8 & 95,3 & 94,6 & 95,9 & 94,4 & 94,9 & 94,2 & 95,3 & 96,7 \\
\hline
\end{tabular}

*Índice de retenção relativo à série de $n$-alcanos (C8-C20) em coluna HP-5MS. nd: não detectado[retention index on the series of $n$-alkanes (C8-C20) column HP-5MS. nd: not detected]. 
proporcionou os maiores acúmulos de biomassa seca da parte aérea e da parte subterrânea na segunda colheita. Os resultados obtidos por Lima et al. (2011) sobre a influência da intensidade de luz no crescimento de mil folhas corroboram com os apresentados neste trabalho, pois demonstraram que o sombreamento a $75 \%$ reduziu o acúmulo de BPA em torno de $50 \%$.

A intensidade e a qualidade espectral da luz influenciaram sobremaneira os teores de pigmentos em mil folhas. A análise dos pigmentos mostrou que, à exceção da clorofila $a$, houve diferenças significativas para os teores de clorofilas $b$, total e carotenóides entre os tratamentos. Notou-se também que a razão clorofila $a / b$ foi menor para aluminet e malha preta, o que significa que os teores foliares de clorofila $b$ foram maiores nesses ambientes. Os resultados do presente estudo corroboram com os de Lima et al. (2011) que verificaram que plantas de mil folhas submetidas a condições de baixas luminosidades continham maiores teores de clorofila $b$. As menores intensidades luminosas foram observadas nos ambientes das malhas vermelha e azul $\left(850 \mu \mathrm{mol} \mathrm{m} \mathrm{m}^{-2} \mathrm{~s}^{-1}\right)$, onde a seletividade espectral também estava presente, o que pode ter acarretado menores teores de clorofila $b$ e total em comparação com a aluminet e malha preta. A aluminet é empregada para o controle térmico devido ao bloqueio da radiação infravermelha, mas não altera os comprimentos de onda nas faixas do azul e do vermelho. A malha preta reduz a intensidade de luz que chega às plantas, não afetando a composição espectral e o conteúdo de luz difusa (Polysack, 2011).

Quanto aos teores de carotenoides, observou-se que a malha azul possibilitou a maior concentração desses pigmentos nas folhas de mil folhas. A luz azul é importante em processos de síntese de pigmentos, enzimas, desenvolvimento de cloroplastídeos, abertura e fechamento estomático e de diversos outros processos foto morfogênicos (Taiz \& Zeiger, 2004). As variações observadas nos teores de pigmentos fotossintetizantes sugerem que plantas de mil folhas dispõem de estratégias de adaptação às modificações cromáticas e de intensidade luminosa, a fim de melhorar seu desempenho fotossintético.

Quanto aos teores de açúcares solúveis totais, observou-se que as plantas cultivadas em pleno sol e malha preta apresentaram as maiores concentrações (Tabela 1). Entretanto, independente do tratamento, os teores de açúcares solúveis totais foram cerca de 7 a 10 vezes superiores na parte subterrânea em relação às folhas, indicando maior alocação desses carboidratos para a parte subterrânea da planta. Isso se explica porque, nas plantas, a sacarose é o principal açúcar exportado dos locais de síntese (folhas) para as regiões de consumo (caule, gemas, raízes e órgãos reprodutivos) onde será utilizada para o crescimento e/ou armazenamento (Chaves-Filho \& Stacciarini-Seraphin, 2001). O fato da mil folhas propagar-se por rizomas pode explicar a maior alocação de açúcares para a parte subterrânea. O teor de amido em mil folhas também foi acumulado em maior quantidade nas raízes do que nas folhas, sendo maior nas plantas cultivadas ao pleno sol, aluminet e malha preta.

O óleo essencial de mil folhas caracterizou-se por possuir alta viscosidade e intensa coloração azul, à exceção das plantas cultivadas sob a malha azul em que o óleo estava mais denso e com coloração azul-esverdeada. Não houve diferença para o teor de óleo essencial das plantas cultivadas sob as diferentes malhas na primeira colheita. Porém, o rendimento do óleo essencial foi superior nas plantas sob as malhas vermelhas e a aluminet em decorrência da maior produção de biomassa (Tabela 1). Independente do ambiente, a mil folhas apresentou maiores teores e rendimento de óleo essencial na segunda colheita. Comparando-se os teores entre a primeira e a segunda colheitas, observou-se produção de óleo essencial de 1,6 a 2,5 vezes superiores na segunda colheita entre os ambientes protegidos. Entretanto, na segunda colheita, tanto o teor quanto a produção do óleo essencial no ambiente a pleno sol foi estatisticamente superior àqueles observados entre os ambientes protegidos devido, principalmente, ao maior acúmulo de biomassa seca da parte aérea. Em estudos em que se avaliou o teor de óleos essenciais em plantas medicinais, foi observado que é variável o comportamento das espécies em resposta à qualidade e intensidade de luz. Silva et al. (2006) verificaram aumento no teor e produção de óleo essencial com o aumento da intensidade da luz em Baccharis trimera. Brant et al. (2009) relataram que Melissa officinalis foi sensível à malha vermelha, afetando negativamente o teor e o rendimento de óleo essencial. Plantas de Mentha piperita cultivadas em pleno sol e sob malhas preta e vermelha produziram maior biomassa seca de folhas e maiores teores e rendimentos do óleo essencial (Costa et al., 2012).

O óleo essencial de mil folhas apresentou, aproximadamente, 50 constituintes químicos (Tabela 2), representando em média 95\% dos constituintes presentes no óleo, sendo caracterizado por alta porcentagem de sesquiterpenos (86,6 a $93,9 \%)$.

Variações expressivas na qualidade e quantidade dos constituintes químicos do óleo essencial entre os tratamentos e as épocas de colheita foram observadas. Dentre outras diferenças qualitativas, observou-se que o óxido de himachaleno foi detectado nas amostras da primeira colheita sob as malhas preta e vermelha e da segunda colheita ao pleno sol, não sendo observado nas demais. Os constituintes $\alpha$-terpineol, aromadendreno e $\alpha$-calacoreno foram detectados apenas nas amostras da segunda colheita sob todas as malhas avaliadas e sob pleno sol. Dentre as alterações quantitativas mais significativas, destacaram-se os teores de monoterpenos totais entre a primeira e a segunda colheitas. $\mathrm{Na}$ primeira colheita, para os ambientes da malha preta, azul e vermelha, os teores de monoterpenos foram menores que $2,0 \%$ e na aluminet, foi de 7,6\%. O maior teor de monoterpenos totais ocorreu no cultivo a pleno sol $(8,5 \%)$. Entre os constituintes químicos presentes no óleo, também foram observadas consideráveis diferenças quantitativas, tais como o $\beta$-cubebeno com teores entre 3,8 e $18,2 \%$ e o acetato de $\alpha$-bisabolol que, embora não tenha sido detectado no óleo sob a malha azul na segunda colheita, cujos teores nos demais tratamentos variaram entre 1,1 e 10,2\%.

O camazuleno, responsável pela co- 
loração azul do óleo essencial de mil folhas, foi o constituinte majoritário, com teores que variaram entre 19,9 e 46,9\%. As folhas das plantas que apresentaram os maiores teores de camazuleno foram daquelas cultivadas sob a malha azul e aluminet, os quais não apresentaram diferenças expressivas quanto ao teor a pleno sol. À exceção da malha vermelha, notou-se também que o teor de camazuleno na segunda colheita foi superior ao da primeira. A sesquiterpenolactona camazuleno e outros sesquiterpenos, tais como $\alpha$-bisabolol, óxido de bisabolol A e farneseno são atribuídas atividades anti-inflamatória, antibacteriana e anti-fúngica (Ganzera et al., 2006).

Pesquisas sobre a composição química do óleo essencial de mil folhas identificaram $\alpha$-pineno, $\beta$-pineno, $\beta$-cariofileno, 1,8-cineol, $\alpha$-felandreno, camazuleno, $\beta$-mirceno, canfora e $E$ -nerolidol como principais constituintes (Gudaityte \& Venskutonis, 2007; Kotan et al., 2010); porém, em nenhum estudo, verificou-se a influência da qualidade luminosa na composição química do óleo essencial.

Em conclusão, o acúmulo máximo de biomassa seca da parte aérea e o maior rendimento de óleo essencial das folhas da mil folhas foi observado na condição de pleno sol, além de conservar a sua composição química. Logo, mil folhas não necessita de cultivo protegido sob malhas coloridas.

\section{AGRADECIMENTOS}

Os autores agradecem à FAPEMIG, CNPq e CAPES, pelo apoio financeiro e concessão de bolsas de estudo e produtividade em pesquisa.

\section{REFERÊNCIAS}

ADAMS RP. 2007. Identification of essential oil components by gas chromatography/mass spectrometry. Illinois: Allured, 804 p.

ALLEN SE; GRIMSHAW HM; PARKINSON JA; QUANMBY C. 1974. Chemical analysis of ecological materials. Oxford: Blackwell Scientific. 565p.

BRANT RS; PINTO JEBP; ROSA LF; ALBUQUERQUE CJB, FERRIPH; CORRÊA RM. 2009. Crescimento, teor e composição do óleo essencial de melissa cultivada sob malhas fotoconversoras. Ciência Rural 39: 1401-1407.

BRASIL. Ministério da Saúde. DAF/SCTIE. 2009. RENISUS.Relação Nacional de Plantas Medicinais de Interesse ao SUS. Fev. 2009. Disponível em: <http://189.28. 128.100/portal/ saude/profissional/vi $>$. Acessado em 09 de maio de 2010.

BRASIL. Ministério da Saúde. Agência Nacional de Vigilância Sanitária. 2010. Resolução RDC $\mathrm{n}^{\circ} 10$ de 09.03.2010. Dispõe sobre a notificação de drogas vegetais junto à Agência Nacional de Vigilância Sanitária e dá outras providências. Diário Oficial da União, Brasília, 10 de março.

CHAGAS JH; PINTO JEBP; BERTOLUCCI SKV; FERRAZ EO; BOTREL PP; SANTOS FM. 2010. Produção de biomassa seca em plantas de Mentha arvensis cultivada sob malhas fotoconversoras. Horticultura Brasileira 28: S3422-S3427.

CHAVES FILHO JT; STACCIARINI-SERAPHIN E. 2001. Alteração no potencial osmótico e teor de carboidratos de carboidratos solúveis em plantas jovens de lobeira (Solanum lycocarpum) em resposta ao estresse hídrico. Revista Brasileira de Botânica 24: 199-204.

COSTA AG; CHAGAS JH; PINTO JEBP; BERTOLUCCI SKV. 2012. Crescimento vegetativo e produção de óleo essencial de hortelã-pimenta cultivada sob malhas. Pesquisa Agropecuária Brasileira 47: 534540.

COSTA LCB; PINTO JEBP; CASTRO EM; ALVES E; ROSAL LF; BERTOLUCCI SKV; ALVES PB; EVANGELINO TS. 2010. Yield and composition of the essential oil of Ocimum selloi cultivated under colored netting. Journal of Essential Oil Research 22: 34-39.

FERREIRA DF. 2011. SISVAR 5.0. sistema de análise estatística. Lavras: UFLA. Software.

GANZERA M; SCHNEIDER P; STUPNNER H. 2006. Inhibitory effects of the essential oil of chamomile (Matricaria recutita) and its major constituents on human cytochrome P450 enzymes. Life Sciences 78: 856-861.

GUDAITYTE O; VENSKUTONIS PR. 2007. Chemotypes of Achillea millefolium transferred from 14 different locations in Lithuania to the controlled environment. Biochemical Systematics and Ecology 35:
$582-592$

HENRIQUE PC; ALVES JG; DEUNER S; GOULART PFP; LIVRAMENTO DE. 2011. Aspectos fisiológicos do desenvolvimento de mudas de café cultivadas sob telas de diferentes colorações. Pesquisa Agropecuária Brasileira 46: 458-465.

KOTAN R; CAKIR A; DADASOGLU F; AYDIN T; CAKMAKCI R; OZER H; KORDALI S; METE, E; DIKBAS N. 2010. Antibacterial activities of essential oils and extracts of Turkish Achillea satureja and Thymus species against plant pathogenic bacteria. Journal of the Science of Food and Agriculture 90: 145-160.

LI JC. 2006. Uso de mallas en invernaderos. Horticultura Internacional. n.extra: 87-90.

LICHTENTHALER HK; BUSCHMANN C. 2001. Chorophylls and carotenoids: measurement and characterization by UVVIS spectroscopy. In: WROLSTAD RE (ed). Current protocols in food analytical chemistry. Madison: John Wiley \& Sons. p. 431-438.

LIMA MC; MARANTE L; MARIOT MP; SERPA R. 2011. Crescimento e produção de pigmentos fotossintéticos em Achillea millefolium cultivada sob diferentes níveis de sombreamento e doses de nitrogênio em milfolhas. Ciência Rural 41: 45-50.

MEIRA MR; MARTINS ER; MANGANOTTI AS. 2012. Crescimento, produção de fitomassa e teor de óleo essencial de melissa (Melissa officinalis) sob diferentes níveis de sombreamento. Revista Brasileira de Plantas Medicinais 14: 352-357.

NIST - NATIONAL INSTITUTE OF STANDARDS AND TECHNOLOGY. 2008. PC version 2.0 of the NIST/EPA/NIH mass spectral library. Gaithersburg. Software.

NOMURA ES; LIMA JD; RODRIGUES DS; GARCIA VA; FUZITANIL EJ; SILVA SHM. 2009. Crescimento e produção de antúrio cultivado sob diferentes malhas de sombreamento. Ciência Rural 39: 1394-1400.

POLYSACK INDÚSTRIAS Ltda. s.d. 2011, 04 de março. Malhas termorefletoras aluminizadas. Disponível em: <http://www.polysack.com>.

SILVA FG; PINTO JEBP; CARDOSO MG; NASCIMENTO EA; NELSON DL; SALES JF; MOL DJS. 2006. Influence of radiation level on plant growth, yield, and quality of essential oil in carqueja. Ciência $e$ Agrotecnologia 30: 52-57.

TAIZ L.; ZEIGER E. 2004. Fisiologia vegetal. 3. ed. Porto Alegre: Artmed, 719 p.

YEMM EW; WILLIS AJ. 1954. The estimation of carbohydrates in plants extracts by anthrone. Biochemical Journal 57: 508-514. 